\title{
(Multi)letramento(s) digital(is) e teoria do posicionamento: análise das práticas discursivas de professoras que se relacionaram com as tecnologias da informação e comunicação no ensino público*
}

\section{Digital (Multi)literacy(ies) and Positioning Theory: Analysis of Discursive Practices of Teachers Involved with Information and Communication Technologies in the Public Education}

Fabiano Santos Saito**

Universidade Federal de Juiz de Fora

Juiz de Fora - Minas Gerais / Brasil

Patrícia Nora de Souza Ribeiro***

Universidade Federal de Juiz de Fora

Juiz de Fora - Minas Gerais / Brasil

RESUMO: O objetivo deste trabalho é analisar as práticas discursivas de três professoras que se relacionaram direta e indiretamente com as Tecnologias da Informação e Comunicação (TICs) no processo de ensino-aprendizagem de uma escola pública na cidade de Juiz de Fora-MG. Para cumprir com esse objetivo, utilizamos o modelo de Multiletramentos Digitais (SELBER, 2004) no que se refere aos usos e práticas sociais da Era Digital. Para enriquecer a análise deste estudo, trouxemos também as contribuiçōes da Teoria do Posicionamento (HARRÉ; VAN LANGENHOVE, 1999), para podermos compreender como as professoras assumiam posiçóes em um contexto de ensino que faz uso das tecnologias digitais. Esta pesquisa de abordagem qualitativo-interpretativista configurou-se metodologicamente como um estudo de caso etnográfico aliado a uma análise do discurso. Os resultados apontam que, embora as professoras assumam em um

\footnotetext{
* A segunda autora, Profa. Dra. Patrícia Nora de Souza Ribeiro, atuou como orientadora do trabalho.

** fabiano_santos_saito@yahoo.com.br

*** patnora.souza@gmail.com
} 
primeiro momento uma posição tecnófila (ou seja, uma posiçāo favorável ao uso das TICs em ambiente educacional), essa posição é rejeitada pelas professoras indiretamente relacionadas à sala de informática em posicionamentos (tomadas de posição discursiva) posteriores, em queé possível identificar posições tecnofóbicas (de medo ou resistência às tecnologias), que são indícios de falta de formação docente que tornem o uso das TICs mais eficiente e situado. Além disso, as posiçōes e posicionamentos assumidos pelas professoras indicam um modelo de Letramento Digital Funcional na escola investigada, que é motivado por problemas de infraestrutura informacional e forças institucionais de instâncias sociais superiores à escola. Assim, uma das contribuiçōes teórico-metodológicas deste estudo é relacionar a Teoria do Posicionamento com o Modelo de Multiletramentos Digitais para explicar os discursos que atravessam o contexto em que as TICs são usadas. Além do mais, esperamos contribuir para uma abordagem mais crítica e questionadora desses contextos educacionais, considerando a formação docente como essencial para a apropriação e o uso situado das TICs. Também é nosso intento levantar discussōes transdisciplinares nas áreas de Linguística, Ensino e Tecnologia.

PALAVRAS-CHAVE: Multiletramentos Digitais; Teoria do Posicionamento; Tecnologias da Informação e Comunicação; análise de práticas discursivas docentes; escola pública.

ABSTRACT: The aim of this work is to analyze the discursive practices of three teachers involved both direct and indirectly with Information and Communication Technologies (ICTs) in the teaching-learning process of a public school situated in the city of Juiz de Fora - State of Minas Gerais in Brazil. To accomplish our goal, we used the theoretical model of Digital Multiliteracies (SELBER, 2004), regarding the uses and social practices of Digital Era. To enrich the analyses of this study, we also brought the theoretical contributions of Positioning Theory (HARRÉ; VAN LANGENHOVE, 1999), in order to understand how teachers take positions within a teaching context that uses digital technologies. This is a qualitative-interpretivist research methodologically set as ethnographic case study allied to a discourse analysis. The results points that, although in a first moment all the teachers take a technophile position (i.e., a position in favor of use of ICTs in educational environment), this position is rejected by some teachers indirectly involved with Computer Lab in later positionings (discursive positions takings), in which it is possible to identify technophobic positions (fear or resistance to digital technologies), that are indices of lack of teacher training oriented for more effective and situated use of ICTs in classrooms. Furthermore, the positions and positionings taken by teachers indicate a Functional Digital Literacy model in the school investigated, which is motivated by informational infrastructure troubles and institutional forces from social instances above the school. One of theoretic-methodological contributions of this study is to relate the Position Theory to the model of Digital Multiliteracies to explain the traversing discourses in the context where ICTs are used. In addition, we hope to contribute focusing on a more critical and questioning approach to these educational settings, highlighting that teacher training is essential for a right appropriation of ICTs and their situated uses. It is also our intent to raise transdisciplinary discussions on Technology, Teaching and Linguistic fields.

KEYWORDS: Digital Multiliteracies; Positioning Theory; Information and Communication Technologies; analysis of discursive practices of teachers; public school. 


\section{Introdução}

Atualmente vivemos em um mundo no qual o uso das Tecnologias de Informação e Comunicação (TICs) torna-se cada vez mais necessário para a participação em diversas instâncias sociais. As relaçôes do homem com a informação e o conhecimento estão sendo modificadas pelo uso do computador e outros dispositivos digitais conectados à internet. Assim, fala-se de uma "Sociedade Informacional" (CASTELLS, 1999), ou de uma "Cibercultura" (LEVY, 1999).

$\mathrm{Na}$ Sociedade Informacional, que emergiu em razão de uma confluência de fatores, sendo os mais destacados o surgimento do computador e da internet e sua consequente popularização, a relação dos homens com as novas tecnologias é preponderante para a participação plena nas instâncias sociais (re)configuradas por essa nova realidade. A presença dos artefatos tecnológicos da Era Digital e sua contínua pervasão na sociedade, processo que parece inexorável, posicionam o homem em meio a um mundo altamente informatizado, repleto de computadores e dispositivos digitais "inteligentes", capazes de falar uma "língua digital", que opera em uma lógica binária capaz de traduzir as várias linguagens humanas: verbais e não verbais (Id., ibid., p. 255).

Dada a presença inexorável das novas tecnologias na sociedade e o processo conflituoso de incorporação das mesmas, Castells (ibid.) indica que ter um domínio ou pelo menos ter conhecimento de tais tecnologias é crucial para o desenvolvimento das sociedades e sua colocação estratégica e decisiva em uma posição sócio-histórica determinante para a realização de transformações sociais, cabendo ao Estado dar fomento à pesquisa (investimento em educação) e desenvolver políticas públicas (provimento de infraestrutura tecnológica).

Nessa nova ordem social digital múltipla, heterogênea, descentralizada e fora de controle propiciada pelas TICs, a identidade docente e a função da educação escolar são postas em xeque. $\mathrm{Na}$ Sociedade Informacional, em que um número cada vez maior de pessoas tem acesso quase ilimitado aos bens simbólicos da humanidade, parece ser redundante a educação preocupar-se apenas com a reprodução de informações na escola. Castells (1999) expõe que a educação assume um papel preponderante para o desenvolvimento tecnológico e a transformação da sociedade na contemporaneidade. No entanto, Teruya (2006) posiciona-se de modo crítico quanto ao assunto e reconhece que somente a educação escolar não tem o poder de mudar a lógica da sociedade capitalista, que preza pela (re)produção de comportamentos alienados. Assim, a autora desloca a função de transformação da realidade social dos aparatos tecnológicos (que sozinhos não são capazes de mudar o contexto em que estão inseridos) e da educação escolar (enquanto sistema 
alienado) para o profissional que pode engendrar essas transformaçōes sociais: o educador tecnológica e criticamente informado. Nesse sentido, a autora apresenta os atributos do professor no contexto mediado pelas TICs:

Neste contexto, o professor deve se apropriar das diferentes linguagens existentes no mundo da mídia, não apenas decifrar os códigos, mas também estar munido de uma interpretação crítica dos conteúdos que circulam nos diversos meios de comunicação. (Id., ibid., p. 81-2)

No entanto, Teruya (ibid.) reconhece a existência de limitações materiais (falta de equipamentos) e limitações humanas: os professores enfrentam uma crise de autoestima causada pelas condições precárias em que trabalham, como a remuneração salarial baixa, cobranças sociais diversas, falta de tempo para complementar uma formação deficiente ou defasada, ausência de metodologias, entre outros problemas.

Delineado esse contexto problemático e complexo, é nossa intenção realizar uma pesquisa para investigar as práticas discursivas de professores que se relacionam direta e indiretamente com as TICs e seu uso em contexto de ensino presencial de escola pública, com o fim de compreender a relação desses professores com as TICs na educação. Este estudo é motivado pela constatação de que poucos trabalhos investigam o assunto e pretende responder a seguinte questão de pesquisa:

1) Quais são as posições assumidas pelos professores quanto ao uso das Tecnologias de Informação e Comunicação em sala de aula?

a. Como essas posições emergem nas práticas discursivas dos professores que se relacionam direta e indiretamente com tais tecnologias?

A fim de responder tal questão, encontramos suporte teórico no modelo de Multiletramentos Digitais (SELBER, 2004), dada a necessidade de o professor ser letrado digitalmente para cumprir com as demandas sociais contemporâneas.

Como o foco da pesquisa é a relação dos professores com as TICs, investigamos as práticas discursivas que emergiram em entrevistas realizadas com tais professores e utilizamos a Teoria do Posicionamento (HARRÉ; VAN LANGENHOVE, 1999), que se configura como um modelo de (micro)análise do discurso, a fim de tentar compreender como os professores se localizam nesse novo cenário educacional em que o uso das TICs se faz necessário.

\section{Uma rede de muitos letramentos}

Antes do surgimento do computador, já havia o conceito de letramento (do inglês literacy) para nomear as práticas sociais de leitura e escrita 
desenvolvidas dentro de uma "cultura do papel" ou "cultura do impresso". Essas práticas possuem objetivos específicos e modificam-se conforme os valores e as ideologias de um contexto peculiar (cf. STREET, 1984; CHARTIER, 1999; KLEIMAN, 1995; SOARES, 2002; 2004; entre outros).

O termo foi "inventado" no Brasil, introduzido como um neologismo por Mary Kato, no intuito de diferenciar alfabetização (processo finito de aquisição do código escrito de uma língua) de letramento (que seriam práticas mais avançadas e socializadas de leitura e escrita). Inicialmente, essa sedimentação teórica fomentou uma dicotomia alfabetização $v s$. letramento, em que este último era privilegiado em detrimento da primeira, muito embora sejam processos complementares e interdependentes (cf. KATO, 1986; TFOUNI, 1988; 1995; SOARES, 2004).

Com a chegada do computador com interface gráfica, da internet e das demais Tecnologias da Informação e Comunicação (TICs), ${ }^{1}$ práticas de leitura e escrita começaram a ser efetuadas por intermédio dessa mídia (meio) eletrônica, o que fez surgir o conceito de "letramento eletrônico" ou "letramento(s) digital(is)", que seria, grosso modo, as práticas sociais de leitura e escrita mediadas pelo computador (cf. SNYDER, 1996; BUZATO, 2001; SOARES, 2002).

No Brasil, por erros de tradução, e para marcar as diferenças que já vinham no plano teórico entre letramento e alfabetização, foi criado o conceito de "alfabetização digital", que seriam os usos mais básicos do computador, em contraste com práticas sociais mais avançadas do uso das TICs (cf. TAKAHASHI, 2000; COSCARELLI, 2007; SOARES, 2002). No entanto, as práticas avançadas do uso do computador, compreendendo inclusive a programação, também podem ser consideradas como "fluência digital" (COMMITTEE ON INFORMATION TECHNOLOGY LITERACY, 1999).

Conceituar letramento(s) digital(is) não é tão simples, pois o desenvolvimento da interface gráfica e do hipertexto - como formas de apresentar a informação através de modos diferentes (usando som, imagem estática e em movimento) associadas por links e até mesmo metáforas visuais (exemplo: desktop = mesa de trabalho; ícones que se referem a suas contrapartes no mundo real, como o que representa "pastas", etc.) - amplia a noção de leitura e escrita do ambiente digital, agregando os letramentos tradicionais ou analógicos aos letramentos visuais,

\footnotetext{
${ }^{1}$ O computador eletrônico surgiu por volta da década de 1930; o protótipo da internet atual, a ARPANET, fez a conexão entre dois computadores em 1969; no entanto, essas tecnologias informacionais só se popularizaram em contexto global por volta da década de 1990 (cf. CASTELLS, 1999; SAITO, 2011).
} 
informacionais, multimidiáticos, hipertextuais em uma rede complexa de múltiplos letramentos (cf. LEMKE, 2002; BUZATO, 2007; 2009; SELBER, 2004; SAITO, 2011; SAITO; SOUZA, 2011; entre outros).

Em vista disso, Selber (2004) propõe uma teoria heurística dos Multiletramentos Digitais, em que três níveis interdependentes e dinâmicos de letramentos computacionais podem ocorrer: o Letramento Digital Funcional; o Letramento Digital Crítico e o Letramento Digital Retórico. Para cada nível há metáforas associativas para computador e posição de sujeito inserido em contexto informacional, bem como há parâmetros e habilidades a serem desenvolvidos, como resume o seguinte quadro:

\section{QUADRO 1}

Esquema resumptivo adaptado do modelo

de Multiletramentos Digitais de Selber (2004)

\begin{tabular}{|c|c|c|c|}
\hline \multicolumn{4}{|c|}{ Multiletramentos Digitais } \\
\hline Nível de LD & LD Funcional & LD Crítico & LD Retórico \\
\hline $\begin{array}{l}\text { Metáfora } \\
\text { relacionada } \\
\text { às TICs } \\
\end{array}$ & TICs como ferramentas & $\begin{array}{c}\text { TICs como artefatos } \\
\text { culturais }\end{array}$ & $\begin{array}{l}\text { TICs como mídia } \\
\text { hipertextual }\end{array}$ \\
\hline \begin{tabular}{l|}
$\begin{array}{l}\text { Posição de } \\
\text { sujeito }\end{array}$ \\
\end{tabular} & $\begin{array}{c}\text { Indivíduos como } \\
\text { usuários competentes }\end{array}$ & $\begin{array}{c}\text { Indivíduos como questio- } \\
\text { nadores de TICs }\end{array}$ & $\begin{array}{l}\text { Indivíduos como } \\
\text { informados das TICs }\end{array}$ \\
\hline 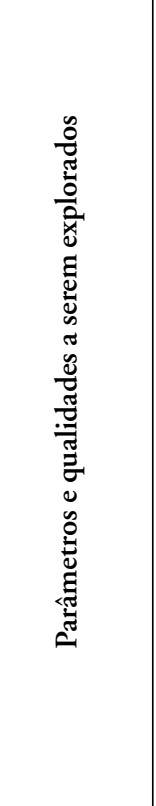 & $\begin{array}{l}\text { 1) Fins educacionais: } \\
\text { atingir objetivos educacio- } \\
\text { nais através das TICs } \\
\text { 2) Convençōes sociais: } \\
\text { entender as convençōes } \\
\text { sociais que determinam os } \\
\text { usos das TICs } \\
\text { 3) Discursos especializados: } \\
\text { usar adequadamente os dis- } \\
\text { cursos associados às TICs } \\
\text { 4) Atividades gerenciais: } \\
\text { gerenciar de modo inteli- } \\
\text { gente o mundo online } \\
\text { 5) Impasses tecnológicos: } \\
\text { resolver os impasses tecno- } \\
\text { lógicos de modo confiante } \\
\text { e estratégico }\end{array}$ & $\begin{array}{l}\text { 1) Culturas de design: inves- } \\
\text { tigar as perspectivas dominan- } \\
\text { tes que constituem as culturas } \\
\text { de design das TICs e seus } \\
\text { artefatos } \\
\text { 2) Contextos de uso: com- } \\
\text { preender os contextos de uso } \\
\text { como aspecto inseparável das } \\
\text { TICs que ajudam a constituí- } \\
\text { las e contextualizá-las } \\
\text { 3) Forças institucionais: } \\
\text { entender as forças institucio- } \\
\text { nais que modelam os usos } \\
\text { das TICs } \\
\text { 4) Representações populares: } \\
\text { investigar as representaçōes } \\
\text { que as TICs têm no imaginá- } \\
\text { rio das pessoas }\end{array}$ & $\begin{array}{l}\text { 1) Persuasão: entender que a } \\
\text { persuasão permeia os contextos } \\
\text { de design de interface, de modo } \\
\text { implícito e explícito, e que isso } \\
\text { sempre envolve forças e estru- } \\
\text { turas maiores (por exemplo, } \\
\text { contextos de uso, ideologias) } \\
\text { 2) Deliberação: entender que } \\
\text { os problemas de design de } \\
\text { interface são problemas mal } \\
\text { definidos, cujas soluções são } \\
\text { argumentos representacionais } \\
\text { aos quais se chega através de } \\
\text { várias atividades deliberativas } \\
\text { 3) Reflexão: articular o conhe- } \\
\text { cimento de design de interface } \\
\text { em um nível consciente e sujei- } \\
\text { tar as ações e práticas à avaliação } \\
\text { crítica } \\
\text { 4) Ação social: compreender o } \\
\text { design de interface como uma } \\
\text { forma de ação social e não } \\
\text { apenas como ação técnica }\end{array}$ \\
\hline
\end{tabular}




\section{Alguns princípios basilares sobre Teoria do Posicionamento e Discurso}

Para mapear como os sujeitos sociais se localizam dentro de discursos e narrativas que permeiam os contextos sociais, utilizaremos a Teoria do Posicionamento (HARRÉ; VAN LANGENHOVE, 1999), uma forma de (micro)análise do discurso desenvolvida pelas escolas anglo-saxãs de análise do discurso. Embora não despreze que os fenômenos sociais se desenrolem através do tempo e do espaço, a Teoria do Posicionamento privilegia os eixos "pessoas" e "conversas" na compreensão dos fatos sociais.

Nesse quadro axiológico, no desenrolar de "conversas" e interaçóes simbólicas similares, pessoas constroem lugares discursivos para si (self) e para os outros - tais posiçôes discursivas podem ser assumidas, rejeitadas e negociadas -, dessa forma, as pessoas conseguem construir o mundo social e agir nele.

Considerando que os fenômenos sociais se constroem e ocorrem através do discurso, a Teoria do Posicionamento o define como "um processo público multifacetado através do qual significados são progressiva e dinamicamente conquistados" (DAVIES; HARRÉ, 1990). Como investigaremos práticas discursivas em contexto escolar, stricto sensu, "o discurso é para ser entendido como um uso institucionalizado de sistemas sígnicos de linguagem e similares" (Id., ibid.).

Outro ponto fundamental na Teoria do Posicionamento é a compreensão da distinção entre posição e posicionamento. Conceitualmente, "posição" configura um lugar social, psicológico e discursivo, a partir do qual as pessoas constroem imagens particulares, narrativas (story lines), metáforas e conceitos relevantes dentro de práticas discursivas (interaçôes simbólicas) entre um eu-si mesmo $\left(\right.$ self $\left.^{2}\right)$ e um outro. Já o "posicionamento" é uma estratégia discursiva que permite às pessoas assumirem, negociarem e rejeitarem posições, ou seja, posicionamento é uma "construção discursiva de histórias pessoais que fazem as açôes de uma pessoa inteligíveis e relativamente determinadas como atos sociais e dentro dos quais os membros de uma conversa têm locações específicas" (HARRÉ; VAN LANGENHOVE, 1999, p. 14).

As interaçóes simbólicas são construídas a partir de três elementos básicos: posição/posicionamentos; narrativas ou story lines; e atos de fala/ações sociais. Em relação às estratégias de posicionamento, apresentamos a seguir um quadro que sintetiza as que podem ocorrer em uma interação simbólica:

\footnotetext{
${ }^{2}$ A rigor, não se traduz o termo inglês "self", entendendo-se que o self é uma representação ou projeção social que criamos de nós mesmos para os outros.
} 


\section{QUADRO 2}

Tipos de Posicionamento, segundo Harré e Van Langenhove (1999)

\begin{tabular}{|l|l|}
\hline \multicolumn{2}{|c|}{ Tipos de posicionamento } \\
\hline $\begin{array}{l}\text { De primeira ordem - é o que estabelece } \\
\text { uma ordem moral, um estado de coisas }\end{array}$ & $\begin{array}{l}\text { De segunda ordem - é o que nega/rejeita } \\
\text { uma ordem moral, um estado de coisas }\end{array}$ \\
\hline $\begin{array}{l}\text { Explicativo - é o que se dá através do uso } \\
\text { de palavras (falar sobre o que foi dito) }\end{array}$ & $\begin{array}{l}\text { Performativo - é o que se dá na forma de } \\
\text { açôes (agir sobre o que foi dito) }\end{array}$ \\
\hline $\begin{array}{l}\text { Moral - é o que se refere mais às funçōes } \\
\text { institucionais ou papéis sociais de um } \\
\text { indivíduo }\end{array}$ & $\begin{array}{l}\text { Pessoal - é o que se refere mais a propriedades } \\
\text { e particularidades pessoais de um indivíduo }\end{array}$ \\
\hline $\begin{array}{l}\text { Do self-é que faz referência a si mesmo } \\
\text { (em geral, marcado linguisticamente por } \\
\text { pronomes de 1a pessoa) }\end{array}$ & $\begin{array}{l}\text { Do outro - é o que faz referência a outro } \\
\text { indivíduo (em geral, marcado linguisticamente } \\
\text { por pronomes de } 2^{\mathrm{a}} \text { e } 3^{\mathrm{a}} \text { pessoas) }\end{array}$ \\
\hline Tácito - sem intenção, inconsciente & Intencional - com intenção, consciente \\
\hline
\end{tabular}

Dentro do posicionamento intencional há uma subcategorização:

\section{QUADRO 3}

Tipos de posicionamento intencional, segundo Harré e Van Langenhove

(1999)

\begin{tabular}{|l|l|}
\hline \multicolumn{2}{|c|}{ Tipos de posicionamento intencional } \\
\hline $\begin{array}{l}\text { Deliberado do self-autoposicionamento } \\
\text { intencional de alguém por si mesmo }\end{array}$ & $\begin{array}{l}\text { Deliberado do outro - alguém posiciona outro } \\
\text { de forma intencional voluntariamente }\end{array}$ \\
\hline $\begin{array}{l}\text { Forçado do self-autoposicionamento } \\
\text { intencional de si demandado por outrem }\end{array}$ & $\begin{array}{l}\text { Forçado do outro - alguém posiciona outro } \\
\text { demandado por outrem }\end{array}$ \\
\hline
\end{tabular}

A Teoria do Posicionamento nos ajudará a identificar as posiçóes assumidas pelas professoras investigadas e localizá-las dentro dos discursos contemporâneos sobre o uso das TICs em contexto educacional.

\section{Relação entre a Teoria do Posicionamento e a informatização das escolas: as posições que os professores podem ocupar na Era Digital}

A partir da observação das práticas e da análise discursiva dos professores que utilizam ou se relacionam com as TICs em ambiente escolar, é possível identificar algumas posições ou lugares de discurso (em um sentido até mesmo mais pragmático) que eles podem assumir, negociar ou rejeitar. 
Em relação ao modelo de Multiletramentos Digitais, Selber (2004) prevê em sua teoria três posições que os sujeitos podem ocupar, segundo o grau de conhecimento e conforto ao utilizar recursos informacionais: 1) letrado digital funcionalmente, ou usuário competente das TICs; 2) letrado digital criticamente, ou questionador das tecnologias informacionais; 3) letrado digital retoricamente, ou produtor reflexivo de tecnologias da Informação, uma vez que domina a retórica das linguagens que estruturam o ambiente digital.

Além disso, outras teorias elaboradas anteriormente, no que se refere ao uso das TICs, estabeleceram posições polares ou dicotômicas que os indivíduos relacionados com o ambiente digital podem ocupar, levando-se em consideração: o grau de conforto/resistência ao uso do computador e similares; e o grau de conhecimento ou intimidade com os dispositivos digitais.

Assim, Campion (1989) revê os conceitos de ciberfilia e ciberfobia (WREGE in VAN TASSEL; VAN TASSEL, 1983 apud CAMPION, 1989), bem como discute a problemática do par de definições tecnocrático vs tecnofóbico ${ }^{3}$ (BADHAM, 1984 apud CAMPION, 1989), preferindo os termos tecnófilo e tecnofóbico como representaçôes simbólicas de classe social daqueles que têm simpatia e facilidade para utilizar as novas tecnologias para o primeiro termo; e daqueles que têm resistência e dificuldade de adaptação em uma sociedade tecnológica para o segundo termo.

Prensky (2001) argumenta que essa facilidade/dificuldade no uso das novas tecnologias vai além da simpatia/resistência aos aparatos digitais. Para o autor, a questão centra-se em uma maior ou menor sensibilização/naturalização do uso das tecnologias digitais no cotidiano, sendo consequente que as gerações nascidas antes da massificação dos computadores teriam mais dificuldades para manuseá-lo - ele define esses indivíduos pré-TICs como "imigrantes digitais". Por outro lado, as gerações que já nascem dentro de contextos sociais altamente informatizados e mostram desde cedo uma propensão natural para usar dispositivos digitais seriam os "nativos digitais".

\footnotetext{
${ }^{3}$ A diferença desse par conceitual é que os tecnocráticos levariam em consideração a razão ao utilizar as novas tecnologias e desse modo obteriam sucesso, enquanto que os tecnofóbicos seriam levados pela emoção ao utilizar computadores e similares, não conseguindo, por isso, êxito na execução de tarefas informacionais.
} 


\section{O encaminhamento da pesquisa}

Metodologicamente, esta pesquisa caracterizou-se como sendo exploratória, de abordagem qualitativa, realizada através de duas estratégias metodológicas associadas: o estudo de caso etnográfico e a (micro)análise do discurso. Caracterizamos a pesquisa como um estudo de caso etnográfico porque satisfaz as condições apontadas por André (1995, p. 31): “[p]ara que seja reconhecido como um estudo de caso etnográfico é preciso [...] que preencha os requisitos da etnografia e, adicionalmente, que seja um sistema bem delimitado", ou seja, em nossa investigação utilizamos métodos da etnografia, como a observação e as entrevistas, além do fato de o contexto de pesquisa ser um "sistema bem delimitado". A (micro)análise do discurso foi escolhida para a fase de tratamento dos dados, mas também para sua posterior seleção, interpretação e análise.

O contexto de pesquisa foi uma escola da rede municipal de ensino de Juiz de Fora-MG localizada em um bairro periférico, situado na Zona Norte da cidade. A escola foi escolhida em razão de possuir um laboratório de informática ativo e de alguns professores estarem trabalhando com um Projeto de Informática Educacional, promovido pela prefeitura em função do Programa Nacional de Informática na Educação (ProInfo). Inicialmente, havíamos convidado os dois professores de Informática da escola, bem como uma professora de língua materna e uma professora de língua estrangeira para participarem da pesquisa. No entanto, ao longo do trabalho, perdemos um professor de Informática (o do turno da manhã, que relatou estar mudando para outra escola à época), além do fato de descobrirmos que as professoras de línguas não tinham qualquer relação com o laboratório de informática. Assim, restou-nos apenas a professora de Informática do turno da tarde, que nos informou sobre as relações que tinha com a professora responsável pela biblioteca da escola e com a professora do $4^{\circ}$ ano do ensino fundamental (cuja turma frequentava a sala de informática). Ao serem convidadas, estas últimas, para participar da pesquisa, ambas aceitaram prontamente. Desse modo, as três professoras pré-citadas tornaram-se os sujeitos de pesquisa deste estudo, sendo identificadas por codinomes (conforme as regras de ética em pesquisa), o que pode ser conferido na tabela a seguir: 


\section{QUADRO 5}

Participantes da pesquisa (SAITO, 2011)

\begin{tabular}{|l|l|}
\hline Nome fictício & Posição institucional \\
\hline Joana & Professora de informática educacional \\
\hline Rosa & Professora regente de turma \\
\hline Márcia & Professora responsável pela biblioteca escolar \\
\hline
\end{tabular}

Além de visitas informais e exploratórias realizadas no segundo semestre de 2009, retornamos à escola no início de 2010 a fim de providenciar a documentação necessária para a realização da pesquisa. As visitas a campo para geração de dados se deram regularmente durante o período de 18 de maio de 2010 até 30 de agosto de 2010, sendo que nesse ínterim houve alguns períodos de descontinuidade: as férias do meio do ano e um breve período de greve dos professores.

Os instrumentos de pesquisa utilizados são descritos na seguinte tabela:

$$
\text { QUADRO } 4
$$

Instrumentos de pesquisa e respectivos objetivos (SAITO, 2011)

\begin{tabular}{|l|l|}
\hline Instrumento de pesquisa & \multicolumn{1}{|c|}{ Objetivo } \\
\hline Observação & $\begin{array}{l}\text { Observar as práticas discursivas e pedagógicas das professoras } \\
\text { investigadas para compreender a ecologia do contexto } \\
\text { investigado, as relaçóes estabelecidas entre as professoras e seu } \\
\text { envolvimento direto e indireto com a sala de informática }\end{array}$ \\
\hline Notas de campo & $\begin{array}{l}\text { Registrar fatos e ocorrências relevantes, na perspectiva do } \\
\text { pesquisador, durante as aulas observadas }\end{array}$ \\
\hline Questionário & Traçar o perfil dos participantes a serem investigados \\
\hline $\begin{array}{l}\text { Entrevistas } \\
\text { semiestruturadas }\end{array}$ & $\begin{array}{l}\text { Possibilitar que os sujeitos investigados se posicionem diante } \\
\text { de questôes sobre Tecnologia e Ensino, relatando suas } \\
\text { narrativas pessoais, experiências, sucessos e dificuldades no } \\
\text { processo de ensino-aprendizagem ao utilizarem as TICs ou se } \\
\text { relacionarem direta ou indiretamente com tais tecnologias e a } \\
\text { sala de informática. }\end{array}$ \\
\hline
\end{tabular}

A aplicação desses instrumentos se deu na seguinte ordem, conforme a adesão das três professoras que aceitaram participar da pesquisa: 1) preenchimento de um questionário diagnóstico; 2) observação das aulas (focalizando as atividades realizadas na sala de informática); 3) tomada de notas de campo; 4) realização de entrevistas. A decisão de aplicar tais instrumentos de pesquisa foi motivada inicialmente pelas características etnográficas do 
estudo. Além disso, utilizar tais instrumentos para geração de dados oportunizou uma compreensão mais holística do contexto investigado e a possibilidade de triangulação de dados, conferindo maior validação e confiabilidade ao estudo.

As entrevistas realizadas foram transcritas segundo as regras da Análise da Conversa Etnometodológica (ACe), formuladas por Sacks, Schegloff e Jefferson (1974; 2005), com algumas adaptações. Devido às limitações de espaço, na análise dos dados apresentaremos apenas alguns excertos das entrevistas, que podem ser conferidas na íntegra nos anexos de Saito (2011).

\section{Análise e discussão dos dados}

Durante a análise, focalizaremos os dados gerados principalmente através de entrevistas semiestruturadas, que possibilitam a elicitação de posições e posicionamentos durante a interação. Como unidade de análise, elegemos o par adjacente de pergunta-resposta, que estabelece dependência funcional e pragmática entre a Primeira Parte do Par (que nesse caso é a pergunta) e a Segunda Parte do Par (a resposta). Isto porque as perguntas feitas pelo pesquisador podem ser entendidas como estratégias de posicionamento de primeira ordem, em que se superpõem posicionamentos intencionais, todos relacionados às narrativas e categorias das teorias sobre uso das TICs na educação, que motivam as participantes da pesquisa a se posicionarem de um modo ou de outro, bem como a própria pergunta disponibiliza posiçôes que podem ser aceitas, negociadas ou rejeitadas pelas entrevistadas.

Em razão disso, alguns tipos de posicionamento são esperados nas práticas discursivas das professoras, como os posicionamentos intencionais (que respondem aos posicionamentos intencionais do pesquisador), posicionamentos do self (porque as perguntas do pesquisador elicitam um posicionamento de um "eu" social das professoras), posicionamentos morais (porque as perguntas são feitas em relação ao lugar institucional de onde as professoras falam), e posicionamentos de segunda ordem (no caso de as professoras discordarem com o que é estabelecido pela pergunta do pesquisador).

Para efetuar a análise, assumiremos que as teorias sobre TICs e ensino, notadamente o modelo de Multiletramentos Digitais (SELBER, 2004), podem ser consideradas como grandes narrativas [storylines], dentro das quais são disponibilizadas posições e atributos (parâmetros) que nos ajudarão a localizar as estratégias de posicionamento usadas pelas professoras que se relacionam com as TICs na escola investigada. 
Sendo assim, responderemos à seguinte questão de pesquisa em nossa análise:

1) Quais são as posições assumidas pelos professores quanto ao uso das Tecnologias de Informação e Comunicação em sala de aula?

a. Como essas posições emergem nas práticas discursivas dos professores que se relacionam direta e indiretamente com tais tecnologias?

De modo geral, evidenciamos que as três professoras investigadas assumem posições tecnófilas quanto ao uso das TICs no processo de ensinoaprendizagem. É dessa forma que Joana, a professora de Informática Educacional, se posiciona quando indagada pelo pesquisador, como mostra o seguinte recorte de entrevista:

Excerto 1 [03:33 - 03:37]

33 Pesq hum(.) eh(.) sobre o uso do computador em ambiente

34 escolar(.) eh(.) qual sua posição? você é a favor? contra?

35 Joana a favor(.) claro! sempre fui a favor(.) e/e daq/ e/e

36 futuramente(.) cada vez mais isso vai ser importante pro

37 aluno ()

Considerando o par adjacente de pergunta-resposta, percebe-se que através de um posicionamento de primeira ordem estabelecido pelo pesquisador (linhas 33 e 34), que é ao mesmo tempo um posicionamento intencional, uma vez que a pergunta de pesquisa tem objetivos inerentes, há a abertura de posições discursivas que são disponibilizadas através de duas polaridades: uma posição favorável (tecnófila) e uma posição de resistência ao uso das TICs na escola (tecnofóbica).

Joana alinha-se à posição tecnófila ao uso das TICs, mais especificamente ao "uso do computador em ambiente escolar", através de um posicionamento explicativo, pois está retomando o que foi dito no posicionamento do pesquisador (linha 35). Como vários modos de posicionamento se superpóem, pode-se dizer que Joana se utiliza também de uma estratégia de posicionamento forçado do self, pois além de responder a um posicionamento intencional do pesquisador, ela se expressa através de uma forma verbal que faz referência ao pronome de $1^{\text {a }}$ pessoa do singular (linha 35: "sempre fui a favor"). Outro índice presente nesta fala de Joana, que representa sua atitude de aceitação e concordância com o uso das TICs no cenário educacional, é o uso da expressão exclamativa "claro!" e do advérbio modalizador "sempre", que reforçam o 
modo como ela se localiza em relação às narrativas sobre "uso de computadores na educação" que circulam na sociedade. A posição tecnófila de Joana se alinha com vários discursos que, em geral, reforçam o lado benéfico dos artefatos tecnológicos no ensino. Isto pode ser entendido como representações populares que as TICs têm na sociedade atual (SELBER, 2004).

Ao cruzarmos os dados dessa fala de Joana com os dados respondidos no bloco 2 do questionário diagnóstico, em que perguntamos sobre a relação da respondente com as Tecnologias da Informação e Comunicação, podemos dizer que a posição tecnófila de Joana é alicerçada por práticas cotidianas e frequentes de uso do computador. Além disso, no questionário Joana aponta que considera importante trabalhar com recursos informacionais na escola, mas que, para tanto, é necessário ter formação nessa área. Ela declara que já possuía esse tipo de expertise antes de trabalhar na escola, o que explica, em parte, seu grau de conforto em trabalhar com o computador na escola e a valoração positiva das TICs no ensino.

Em outra entrevista, sobre uma experiência de Letramento Digital desenvolvida em conjunto com a professora da biblioteca escolar em que foi feita a apresentação do "Livro Virtual" para alunos do $1^{\circ}$ ano do ensino fundamental, Joana confirma a posição favorável ao uso das TICs no ensino por meio de uma narrativa [storyline] que reflete o entusiasmo ao se trabalhar com tais tecnologias junto aos alunos, como ilustra o seguinte trecho:

Excerto 2 [01:02 - 01:24]

02 Pesq

04 Joana a experiência de hoje foi muito boa(.) foi muito proveitoso(.) eu vi que os meninos tiveram eh/eh/eh uma/um interesse na história(.) eh alguns ficaram sem... assim ti/foram dispersos(.) mas muito pouco(.) a maioria(.) soube responder as perguntas(.) do que foi mostrado/na história que foi mostrada(.) a história do/eh "onde estão os meu óculos?”(.) que é uma história pra crianças menores(.) crianças aí numa faixa etária aí(.) de/de três(.) quatro(.) até cinco anos(.) ih/ih eu adorei essa experiência de trabalhar com... o computador(.) o datashow(.) mostrando pra eles essa/essa questão do/do/do livro...

17 Pesq do livro virtual? 
18 Joana do livro virtual(.) que é uma no/foi uma novidade pra 19 eles(.) nunca/nunca terem visto antes(.) eh/eh essa/essa $\rightarrow \quad 20$ questão do livro virtual(.) eu achei maravilhosa a experiência(.) muito boa(.) ih rendeu(.) foi uma aula que rendeu(.) teve um bom rendimento(.) da/na perspectiva de/de ensino(.) de/de qualidade(.) assim(.) de ver os meninos interessados(.) ih/ih/ih aprendendo(.)

A pergunta inicial do pesquisador (linhas 2 e 3 ) configura novamente posicionamento de primeira ordem intencional que elicita o posicionamento da professora, que procede à avaliação positiva do evento através de um posicionamento forçado do self (linha 4 e seguintes, e em especial as linhas 1314, e 20-21), que pode ser verificado através do uso do dispositivo de pronominalização específico para representação do self: Joana se identifica através do pronome "eu". Seu posicionamento também é explicativo, na medida em que se refere ao que foi perguntado pelo pesquisador.

A avaliação positiva, e mesmo entusiasmada, de Joana em relação ao uso de computador em um evento de LD, quando diz "eu adorei essa experiência de trabalhar com... o computador" (linhas 13 e 14) ou "eu achei maravilhosa a experiência(.) muito boa" (linhas 20 e 21), corrobora sua posição tecnófila sobre o uso das TICs no ensino.

As práticas discursivas de Joana se referem aos discursos especializados associados às TICs ("computador", "datashow", "livro virtual") bem como indicam, segundo a avaliação dela, o cumprimento de fins educacionais (linhas 21-24), através do uso de recursos computacionais (linhas 14-16). Esses parâmetros, discursos especializados e fins educacionais, se relacionam ao LD Funcional ou Instrumental (cf. SELBER, 2004) e são indícios do uso desse modelo de LD nas práticas educacionais da escola.

Conforme Joana nos relatou, ela trabalha em um regime de parceria com os professores regentes de turma, que são responsáveis inclusive pelo conteúdo a ser trabalhado com os alunos no ambiente informacional da escola. Devido a limitaçôes de infraestrutura da sala de informática, há um sistema de revezamento: Joana trabalha com meia turma em metade do horário reservado para a classe, enquanto a outra metade fica na sala de aula convencional com o professor regente, aguardando o momento de ir para a sala de informática. Há uma relação indireta do professor regente com a sala de informática, por isso, fizemos uma entrevista com Rosa, professora do $4^{\circ}$ ano do ensino fundamental, cuja turma frequenta a sala de informática em horário 
preestabelecido. Durante a entrevista, ao ser questionada sobre o papel da sala de informática na escola, de certo modo, a Profa. Rosa também revela uma posição tecnófila ao uso de TICs no ensino, como mostra este excerto:

Excerto 3 [01:23 - 01:32]

23 Pesq eh(.) e como que você vê o papel da sala de informática(.)

24 no contexto educacional(.) no contexto aqui da escola?

25 Rosa nossa! de suma importância(.) devido exatamente a 26 essa/essa(.) a introdução $\mathrm{da} / \mathrm{da}$ internet(.) né! da/na/na 27 modernidade(.) eh/eh(.) quantidade de informações que são 28 dadas pros alunos(.) então eu acho que é muito 29 importante(.) pra que eles também(.) se/se né! 30 interajam(.) estejam de acordo com a(.) caminhe junto com 31

32 a realidade(.) com o que tá acontecendo no mundo(.) eu acho que é fundamental

Como sempre, porque as perguntas de pesquisa possuem objetivos implícitos e explícitos, elas se configuram como estratégias de posicionamento intencional, que estabelecem um estado de coisas ou ordem moral em que posições são disponibilizadas para os entrevistados. Nessa pergunta específica (linhas 23 e 24 do Excerto 3), fica claro que o pesquisador elicita um posicionamento da pessoa entrevistada, ao escolher o pronome de tratamento "você" quando se dirige ao entrevistado, mas também ao utilizar verbos epistêmicos; ${ }^{4}$ no caso, o verbo "ver", no sentido de compreender. Esses dispositivos linguísticos têm a intenção de fazer com que o informante da pesquisa assuma uma posição frente ao tema ou tópico da pergunta. Ao mesmo tempo, a questão traz embutida uma demanda para que Rosa posicione a sala de informática dentro da escola.

Sendo assim, Rosa primeiramente atende a essa demanda, dizendo que a sala de informática tem um papel de suma importância na escola (linha 25). Dessa forma, ela própria está assumindo um posicionamento do self, pois está implícita em sua prática discursiva a expressão "eu acho que" que responde à primeira parte da pergunta do pesquisador. Assim, a resposta de Rosa poderia ser glosada como "eu acho que o papel da sala de informática no contexto aqui

\footnotetext{
${ }^{4}$ Verbos epistêmicos são aqueles que indicam processos de atividade mental e opiniāo, como pensar, achar, compreender, ver (no sentido de compreender), etc.
} 
da escola é de suma importância etc. etc.”. Tanto é assim que a própria Rosa sente a necessidade de verbalizar o posicionamento do self através de um pronome de $1^{a}$ pessoa, como pode ser observado nas linhas 28 e 29 ("então eu acho que é muito importante") e nas linhas 31 e 32 ("eu acho que é fundamental"). A elocução das linhas 28 e 29 é um elo discursivo entre tudo o que é dito antes (linhas 25, 26, 27 e 28), em uma relação anafórica, mas também se relaciona a tudo o que é dito depois dela (linhas 29, 30, 31 e 32), em uma relação catafórica. Isso sem falar que toda a elocução de Rosa (desde a linha 25 até a 32) se relaciona ao que foi perguntado pelo pesquisador, sendo, portanto, um posicionamento explicativo.

Rosa justifica sua posição de considerar a sala de informática como de "suma importância" e "fundamental" a partir de três fatores que ela indica em sua prática discursiva: "a introdução da internet na modernidade" (linhas 26 e 27), "a quantidade de informações dadas aos alunos" através da internet (linhas 27 e 28) e a necessidade de o aluno interagir com a realidade instaurada com o surgimento da internet (linhas 30 e 31). Nas linhas 27 e 28, Rosa revela a representação popular de que "a internet oferece uma grande quantidade de informações"; como este é um discurso de consenso, pouco tem sido discutido sobre a qualidade das informações disponíveis na rede, ou seja, há uma necessidade de se explorar uma perspectiva mais crítica em relação aos Letramento(s) Digital(is), no sentido de questionamento em relação à qualidade e aos benefícios (ou malefícios) agregados a esse grande volume de informações disponível na internet - essa abordagem crítica e de questionamento informado, segundo Selber (2004), poderia ser atingido através do Letramento Digital Crítico. Nas linhas 30 e 31, depreende-se que os alunos podem interagir com o mundo e com a realidade através da internet, ficando implícita a ideia de práticas sociodiscursivas mediadas pelas TICs ou Letramento(s) Digital(is).

De tudo isso, conclui-se que Rosa tem uma posição tecnófila quanto ao uso das TICs no ensino, uma vez que tais tecnologias podem ajudar a contextualizar o aluno dentro da nova realidade de uma Sociedade Informacional. Em consonância com esse modo de pensar, a Profa. Márcia que planejou e participou de um evento de letramento digital juntamente com a Profa. Joana - também assume uma posição tecnófila, como evidencia o seguinte fragmento de entrevista: 
Excerto 4 [04:45 - 05:04]

45 Pesq eh(.) então você acha relevante(.) o uso da tecnologia(.)

46 em sala de aula(.) com os alunos?

47 Márcia muito(.) muito relevante(.) até porque(.) nós tamos na era

48 tecnológica(.) né!

49 Pesq hum

$\rightarrow \quad 50$ Márcia e assim(.) e eu s/eu sempre me considerei uma analfabeta

$\rightarrow \quad 51$

$\rightarrow \quad 52$

$\rightarrow \quad 53$ tecnológica(.) por quê?(.) a g/eu sempre tive muito medo de mexer(.) com essa questão do aparelho(.) igual você viu a questão do datashow

54 Pesq hum

55 Márcia mas assim(.) eu to/ eu tô perdendo isso(.) por 56 necessidade(.)por perceber a necessidade

57 Pesq hum

58 Márcia desse tratamento diferenciado da informação(.) né! hoje em

59 dia você(.) não vai proibir o aluno de usar o celular na 60 sala de aula(.) porque o celular pode ser um instrumento [quebra de página na sequência de transcrição]

01 de trabalho(.) de conteúdo(.) pelo/a gama de/de

02 informações que ele pode te(.) trazer(.) né! a questão é

03 saber usar(.) de forma(.) a/a priorizar a questão da

04 educação

Como sempre, a pergunta do pesquisador é um posicionamento de primeira ordem e intencional (linhas 45 e 46). No caso de Márcia, ela se alinha à posição disponível na pergunta, concordando que o uso da tecnologia na sala de aula com os alunos é muito relevante, e justifica sua localização nesse lugar discursivo através de um posicionamento forçado do self- uma vez que é um posicionamento intencional motivado pela pergunta do pesquisador - ao dizer que acha o uso das TICs no ensino muito importante "até porque(.) nós tamos na era tecnológica(.) né!” (linhas 47 e 48 do Excerto 4). Para expressar sua posição, Márcia se utiliza do pronome de $1^{a}$ pessoa, "nós", de modo a indicar que não somente ela, mas várias pessoas participam do processo de inserção no mundo digital desencadeado pelo desenvolvimento das TICs. Esse dispositivo linguístico, ou seja, o uso do pronome "nós", em vez de "eu”, também indica um posicionamento mais moral, enfatizando a opinião dela como professora, do que um posicionamento pessoal. 
Apesar de considerar o uso das TICs no ensino extremamente importante, indicando uma posição tecnófila em relação ao uso dessas tecnologias em ambiente educacional, a partir da linha 50 do Excerto 4, a Profa. Márcia começa a desenvolver uma narrativa pessoal [storyline] em que assume uma posição de "analfabeta tecnológica", alinhando-se aos discursos recorrentes sobre analfabetismo digital ou tecnológico difundidos pela mídia e outras instituições na sociedade (cf. FRADE, 2007). Nesse momento, Márcia utiliza duas estratégias de posicionamento: posicionamento explicativo - porque está se referindo a uma experiência vivida através do uso de palavras (diferente de um posicionamento performativo que se basearia em ações ou gestos) - e posicionamento deliberado do self, pois ela tem a intenção de relatar sua relação com as TICs, assumindo deliberadamente uma experiência pessoal e uma posição de sujeito: observe o uso do pronome de $1^{a}$ pessoa no singular, "eu", que denota a particularização do self na narrativa e um posicionamento mais pessoal (linhas 50 e 51 ).

Márcia justifica sua posição como "analfabeta tecnológica" usando como argumento o medo que ela diz ter em relação ao uso ou manipulação dos equipamentos da tecnologia digital (linhas 51, 52 e 53 do Excerto 4), o que indica um certo grau de tecnofobia: esse medo é comum no cenário educacional. Outro dado que confirma essa posição tecnofóbica de Márcia são as respostas que ela dá à pergunta 36 do questionário, em que ela avalia o próprio conhecimento para uso do computador como sendo insatisfatório, o que pode explicar seu medo ou insegurança diante das TICs. As hipóteses mais razoáveis para a tecnofobia podem ser o desconhecimento de como usar as TICs, quando usá-las e para que usá-las: questôes de (Multi)Letramentos Digitais, e mais especificamente de Letramento Digital Crítico (SELBER, 2004). Estas questôes não estão sendo abordadas na formação dos professores, seja inicial ou continuada, tanto para atuação em escolas públicas ou privadas. Outra hipótese para a tecnofobia é a apreensão que o professor tem ao descobrir que os alunos podem possuir mais facilidade para lidar com TICs, pois são "nativos digitais", do que o próprio professor "imigrante digital" (PRENSKY, 2001), que tradicionalmente ocupa a posição institucional de quem deve ensinar, e não de quem aprende.

Segundo Joana e Rosa, elas trabalham em um sistema de parceria no projeto de Informática Educacional. Ambas assumem posições tecnófilas quanto ao uso das TICs no ensino. No entanto, esse discurso tecnófilo pode ser um "discurso vazio", na medida em que exige dos envolvidos maior 
comprometimento, participação ou engajamento nas atividades desenvolvidas na sala de informática. Observe a opinião de Rosa neste excerto sobre o papel da professora de Informática dentro da escola:

Excerto 5 [01:05 - 01:18]

\begin{tabular}{|c|c|c|}
\hline 05 & Pesq & {$[\ldots] \operatorname{eh}()$.} \\
\hline 06 & & você vê o papel da professora de informática(.) dentro da \\
\hline 07 & & escola? \\
\hline 08 & Rosa & muito importante(.) porque ela trabalha junto(.) dentro do \\
\hline 09 & & conteúdo que a gente trabalha(.) porque é passado(.) é \\
\hline 10 & & feito um planejamento(.) e esse planejamento é passado pra \\
\hline 11 & & ela(.) e eu acho que é muito importante(.) porque a ger \\
\hline 12 & & trabalha junto(.) então(.) dentro de sala de aula(.) eu \\
\hline 13 & & trabalho da forma(.) né! vamos dizer assim(.) "teórica" \\
\hline 14 & Pesq & hum \\
\hline 15 & & Rosa e ela na sala de informática trabalha mais de uma forma(.) \\
\hline 16 & & lúdica(.) né! de uma forma mais(.) descontraída(.) né \\
\hline 17 & & uma coisa lú/ de uma/ assim(.) de uma forma que \\
\hline 1 & & crianças gostam muito $($.$) né!$ \\
\hline
\end{tabular}

Na opinião de Rosa, que é um posicionamento do self e do outro, o papel da professora de Informática é muito importante, e ela ressalta o trabalho que desenvolve em conjunto com Joana (linhas 8-12). Aqui é importante frisar que Rosa diz de modo indireto que ela e os demais professores regentes de turma/disciplina são os responsáveis pelos conteúdos trabalhados na sala de informática: "é feito um planejamento(.) e esse planejamento é passado pra ela [profa. de Informática]” (linhas 9-11).

Assim, infere-se que Rosa posiciona a Profa. de Informática Educacional como aplicadora de atividades, que trabalha o "como fazer", que está intrinsecamente ligado à metodologia de ensino, uma vez que "o que fazer" que demanda escolhas políticas ou cumprimento de um pacote de decisões estabelecidas -, já foi pré-definido por outrem. Essas decisóes acerca do conteúdo que deve ser trabalhado na sala de informática podem ser entendidas como forças institucionais que determinam o contexto de uso das TICs na escola (SELBER, 2004). Talvez isso aconteça por ser a Profa. de Informática detentora de um saber que é novo, isto é, trabalhar com os recursos das TICs. Desse modo, resta-lhe uma função técnica, de especialista, por conta desta expertise diferenciada. 
Além disso, Rosa se autoposiciona como professora que trabalha na sala de aula convencional de uma forma "teórica", ao mesmo tempo que posiciona Joana como professora que trabalha o mesmo conteúdo (ou o mesmo tema) na sala de informática de uma forma "lúdica [...] uma forma mais(.) descontraída" (linhas 13-16).

Embora esse posicionamento do self que Rosa assume para si e o posicionamento do outro que ela emite sobre Joana pareçam banais e emerjam na prática discursiva de uma forma aparentemente inocente, essas estratégias discursivas de Rosa podem estar encobrindo ideologias e valores subjacentes, pois quando é criada uma comparação, podem se iniciar dicotomias perigosas, do tipo sala de aula convencional $v$ s. sala de informática; trabalhar o conteúdo de forma "teórica" (= trabalho sério) vs. trabalhar o conteúdo de forma "lúdica" (= trabalho que não é sério). E ao estabelecer essas diferenças, Rosa acaba revelando que o trabalho entre o professor regente e o professor de Informática não é tão integrado como ela frisa nas linhas 8-12.

Tanto é assim que a própria Rosa reorganiza sua elocução sequencialmente: assim que acaba de enunciar "forma lúdica" (linhas 15-16), reenuncia em seu lugar "forma mais descontraída" (linha 16) e depois "forma que as crianças gostam muito" (linhas 17-18). Essas opiniōes que Rosa emite sobre as atividades que Joana desenvolve na sala de informática, por sua vez, posicionam essas atividades como sendo lúdicas. Considerando o público-alvo que Joana e Rosa atendem - alunos do $4^{\circ}$ ano do ensino fundamental -, não é problema pensar que o lúdico ainda desempenha um papel importante nas crianças dessa faixa etária, que muitas vezes "aprendem brincando".

O problema está em posicionar a sala de informática como lugar apenas de diversão e entretenimento, quando deveria ser espaço também para se pensar e trabalhar as questôes até mesmo de fundo moral e ético que podem estar encobertas em web pages, jogos da internet, perfis de redes sociais, e demais sites do ambiente digital. Se a educação ocorre a todo momento, de algum modo, os alunos das escolas da rede pública deveriam ser alertados sobre os perigos e as armadilhas que podem estar escondidos sob recursos hipermidiáticos aparentemente inocentes. Por isso a necessidade de se trabalhar modelos de LD que levem em conta aspectos críticos e de organização discursiva através das TICs, o Letramento Digital Crítico (SELBER, 2004).

A separação entre as atividades mais "teóricas" trabalhadas na sala de aula pela Profa. Rosa em contraposição a atividades mais "lúdicas" desenvolvidas pela Profa. Joana na sala de informática, que emerge nas elocuções de Rosa, 
indica que cada professora trabalha o mesmo conteúdo ou tema de forma diferente e separada, o que pode sinalizar que o professor regente não se envolve ou se compromete muito com as atividades da sala de informática. Isso talvez possa ser explicado até mesmo pela falta de conhecimentos de Informática por parte do professor regente: Rosa, por exemplo, na pergunta 33 do Questionário diagnóstico, que indaga se ela havia recebido alguma capacitação para trabalhar com Informática em sala de aula, responde que não. Nesse sentido, o professor regente não se enxerga em uma posição de professor que se utiliza dos recursos das TICs para fins de ensino-aprendizagem, como pode ser verificado neste fragmento:

Excerto 6 [01:34-01:42]

34 Pesq

35

36

37

38

39

40

41

42

43 Pesq

44

45

46

47

48

50

51

52

53

54

55

56

4

[...]eh(.) e assim(.) se fosse pra você assumir(.) as aulas na sala de informática(.) você se sentiria preparada?

Rosa não(.) de forma alguma(.) a menos que houvesse(.) né! por parte(.) no caso(.) da prefeitura(.) um preparo para que os professores regentes visse essa parte(.) mas como isso não acontece(.) né! então assim(.) eu não me sinto preparada(.) acho que eh/eh o papel(.) por isso(.) o papel da professora de informática é vital

$\operatorname{sim}($.$) mas você acha importante se a prefeitura te desse$ uma formação(.) pra trabalhar com tecnologia(.) digital em sala de aula?

Rosa é eu acho que até seria

Pesq Hum

Rosa só que(.) o tempo da gente é muito restrito(.) né! do professor regente(.) são tantos conteúdos que a gente tem que trabalhar

Pesq Hum

Rosa então(.) eu acredito que também eh/eh seria importante(.) o professor(.) o próprio o professor de informática(.) que já é formado pra isso(.) ele trabalhar nessa parte(.) ajudando a gente nessa/nessa questão(.) né! trabalhando em conjunto com a gente

Quando o pesquisador, através de seu posicionamento intencional, pergunta a Rosa se ela se sente preparada para assumir aulas na sala de 
informática, ela rejeita imediatamente essa posição através de expressões categóricas de negação: "não(.) de forma alguma" (linha 37). Como ela não se identifica com a posição que é disponibilizada no posicionamento de primeira ordem do pesquisador, ela reage utilizando-se de um posicionamento de segunda ordem que, em um primeiro momento nega a posição disponibilizada e inicia a negociação da posição através de dispositivos linguísticos que indicam concessão: "a menos que houvesse(.) né! por parte(.) no caso(.) da prefeitura(.) um preparo para que os professores regentes visse essa parte [de Informática, de aplicação das TICs no ensino, de LD] mas como isso não acontece" (linhas 37-40).

Essa posição tecnofóbica ou de resistência de Rosa em assumir a função de professor de Informática, ou até mesmo de medo diante dessa responsabilidade, se explica pela falta de formação para trabalhar com as TICs: "a menos que houvesse(.) né! por parte(.) no caso(.) da prefeitura(.) um preparo para que os professores regentes visse essa parte [de Informática, de aplicação das TICs no ensino, de LD] mas como isso não acontece" (linhas 37-40). Nessa elocução, Rosa posiciona a prefeitura como responsável por oferecer tais conhecimentos de Informática aos professores regentes. No entanto, ela aponta que essa formação não acontece.

Ao ser questionada sobre a importância de a prefeitura oferecer essa formação para ela trabalhar com as TICs no ensino (linhas 43-45), inicialmente Rosa se alinha com a ideia, concordando que isso seria importante (linha 46). Mas em seguida ela discorda, com um posicionamento de segunda ordem em que discorre sobre a falta de tempo como fator limitante ou empecilho para a realização de uma formação continuada que lhe preparasse para o trabalho com as TICs no ensino (linhas 48-50). Rosa inclusive constrói uma narrativa [storyline] de vitimização, ou seja, ao dizer "o tempo da gente é muito restrito(.) né! do professor regente(.) são tantos conteúdos que a gente tem que trabalhar", ela posiciona seu self, enfatizando o posicionamento moral de professora, como vítima do sistema educacional que a obriga a trabalhar com muitos conteúdos (muitas disciplinas, muitas informaçôes), de modo que não lhe sobra tempo nenhum para realizar cursos de formação continuada.

Logo depois, Rosa assume uma posição de isenção de responsabilidade em relação ao trabalho com as TICs, quando justifica sua falta de preparo para lidar com recursos informacionais: "por isso o papel da professora de informática é vital” (linhas 41-42). Ela reforça essa posição com argumento semelhante nas linhas 52-56. 
De modo indireto, através desses posicionamentos de segunda ordem, a Profa. Rosa diz que não quer se preocupar com esses assuntos relacionados às TICs no ensino, justificando, desse modo, a presença do professor de Informática no contexto escolar; alguém que preenche, devido à formação especializada, uma posição institucional emergente no cenário educacional. Essas práticas discursivas são indício do pouco envolvimento do professor regente nas ações desenvolvidas na sala de informática.

No entanto, acreditamos que o conhecimento de TICs e das várias formas de Letramento(s) Digital(is) como formas de inclusão social e apropriação crítica das tecnologias digitais torna-se necessário não somente ao professor de Informática, mas aos professores de disciplinas diversas, para promoção do processo de ensino-aprendizagem através das novas tecnologias que são demandadas pela Sociedade Informacional na qual vivemos.

Sobre o oferecimento ou não de cursos de formação continuada para se trabalhar com as TICs, as três professoras investigadas assumem posiçóes diferentes e conflitantes. Como vimos no Excerto 12, Rosa diz que a prefeitura não promove esse tipo de formação. No entanto, a Profa. Márcia diz o oposto, como evidencia este trecho:

Excerto 7 [05:07 - 05:15]

07 Pesq mas assim(.) pra saber utilizar então esses recursos(.)

08 né! tecnológicos(.) você acha que é necessário o professor

09 se antenar(.) e ter uma formação(.) eh(.) sobre as

10 tecnologias(.) no ensino?

11 Márcia éverdade

12 Pesq hum

13 Márcia e isso assim(.) é até a secretaria municipal de educação

14 nos oferece

15 Pesq hum

16 Márcia ela nos oferece um curso de informática na educação

Como se vê, através de um posicionamento intencional, quando o pesquisador pergunta se seria importante o professor ter uma formação para trabalhar com TICs no ensino (linhas 7-10 do Excerto 13), a Profa. Márcia concorda, alinhando-se ao posicionamento de primeira ordem do pesquisador. Na sequência de sua elocução, ela explica que a Secretaria Municipal de Educação oferece um curso de informática na educação (linhas 13, 14 e 16). Isto põe em xeque o que foi dito pela Profa. Rosa no Excerto 6, ou seja, que 
a prefeitura não oferece cursos de Informática aplicada à Educação para os professores regentes.

\section{Considerações finais}

Os dados analisados apontam que as três professoras investigadas assumem uma posição tecnófila ou favorável em relação ao uso das TICs em sala de aula, pelo menos no plano discursivo: Joana, por ser a professora de informática, possui um alto grau de tecnofilia, tanto no discurso quanto na prática; Márcia, professora responsável pela biblioteca, tornou-se tecnófila por compreender a necessidade dos conteúdos informacionais na educação, mas sua simpatia pelas TICs é apenas discursiva, pois confessa que, na prática, ainda possui certa tecnofobia; e Rosa, embora reconheça a importância das TICs no ensino (tecnófila no discurso), possui alto grau de tecnofobia só de pensar em assumir atividades que façam uso do computador e similares, repassando tal responsabilidade a quem tenha formação especializada.

As posições assumidas pelas professoras investigadas emergem através de estratégias de posicionamento que se desenvolvem em narrativas [storylines], nas quais as professoras tornam relevantes informaçōes pessoais e profissionais relativas ao uso das TICs, bem como as representaçóes particulares que as TICs têm em suas vidas e experiências, ou seja, em suas práticas cotidianas inseridas na atual Sociedade da Informação.

Através da análise dos dados, evidenciamos que, em geral, as professoras se utilizam dos seguintes modos de posicionamento: posicionamento forçado do self-porque respondem a uma pergunta intencional do pesquisador; posicionamento explicativo - porque mantêm uma relação com o que foi dito ou indagado pelo pesquisador; posicionamento moral - porque as professoras tornam relevantes em suas práticas discursivas seus atributos institucionais ou profissionais. Com frequência, as professoras se alinham ou se identificam com as posições disponibilizadas pelas perguntas. No entanto, os dados apontam que em alguns casos, as entrevistadas questionam a ordem moral ou o estado de coisas estabelecido na pergunta, fazendo uso de um posicionamento de segunda ordem, quando negociam ou rejeitam posiçóes.

Considerando as posições assumidas pelas professoras em suas práticas discursivas e o contexto de uso das TICs na escola investigada, tentamos localizar essas posições em referência aos parâmetros do modelo de Multiletramentos Digitais proposto por Selber (2004). Nesse sentido, os resultados apontam para o predomínio dos parâmetros relacionados ao nível de Letramento Digital Funcional, quais sejam: 
1) o uso de discursos especializados associados às TICs (ou seja, o uso de todo um campo semântico diretamente relacionado aos artefatos digitais), uma vez que as professoras se referem a tais tecnologias em suas práticas discursivas (por exemplo, falam de computadores, datashow, planilhas, digitar, etc.);

2) a indicação de que se preocupam em atingir fins educacionais através do uso das TICs;

3) impasses tecnológicos, que se configuram como falta de formação para trabalhar adequadamente com recursos computacionais, no caso das professoras que demonstram tecnofobia.

Ao cruzarmos os dados obtidos nos questionários, nas entrevistas e no período de observação das atividades realizadas na sala de informática da escola pesquisada, podemos dizer que, embora a Profa. Joana seja da geração de "imigrantes digitais", por meio de um empenho ou engajamento em sua formação continuada (através da realização de cursos na área de Informática), ela conseguiu atingir certa "fluência digital" para trabalhar com as TICs em um nível de Letramento Digital Funcional, o que já é um avanço na aplicação das novas tecnologias no processo de ensino-aprendizagem na educação presencial em contexto de escola pública no Brasil. Isso reforça o que a literatura da área tem dito sobre a necessidade de formação docente adequada para um uso mais eficiente e situado das TICs na educação. A partir disso, também há que se pensar em alternativas para o ensino que integrem e se direcionem para níveis mais avançados de Letramento(s) Digital(is), como o LD Crítico e o LD Retórico.

A explicação razoável do contexto de uso das TICs na escola investigada, bem como a compreensão dos discursos que atravessam tal contexto e que fazem as professoras se posicionarem de modo peculiar, deve-se à conjugação da Teoria do Posicionamento (HARRÉ; VAN LANGENHOVE, 1999), eminentemente etnográfica, com o modelo de Multiletramentos Digitais (SELBER, 2004), fundamentado no tecnológico, que apontamos como contribuição teóricometodológica para as áreas de Linguística, Ensino e Tecnologia.

A título de conclusão, podemos dizer que os dados analisados em nosso estudo mostram como está intimamente relacionada a formação do professor complementada por cursos da área de Informática com as práticas letradas digitais efetivas e o grau de conforto em utilizar as TICs na educação (como no caso da Profa. Joana); por outro lado, a falta de formação docente voltada para a integração das TICs na educação acaba gerando tecnofobia (como no caso da Profa. Márcia), bem como insegurança e resistência (como no caso da Profa. Rosa). Fazem-se necessários, portanto, a ampliação e desenvolvimento 
de programas que ofertem oportunidades para que os professores se apropriem de práticas letradas digitais voltadas especificamente para o ensino e o trabalho em sala de aula: a formação continuada deve ser estimulada bem como a valorização docente. A tentativa de compreensão das relações complexas que se estabelecem entre as TICs e os contextos de educação pública que este estudo buscou alcançar aponta para a necessidade de políticas de planejamento e melhoria das estruturas informacionais das escolas públicas; do duplo investimento tanto em equipamentos necessários para inclusão efetiva das TICs no ensino quanto na formação humana adequada para atender à demanda de promoção de (multi)letramento(s) digital(is); de ampla discussão acadêmica e política sobre a função das TICs na apropriação dos bens culturais da Sociedade Informacional, no desenvolvimento social e tecnológico, bem como na conquista de cidadania digital plena.

\section{Referências}

BUZATO, M. E. K. Entre a fronteira e a periferia: linguagem e letramento na inclusão digital. 2007. 284 f. Tese (Doutorado) - Instituto de Estudos da Linguagem, Universidade Estadual de Campinas, Campinas, SP. Disponível em: <http:// libdigi.unicamp.br/document/?down=vtls000415042>. Acesso em: 15 jan. 2010 . BUZATO, M. E. K. Letramento e inclusão: do estado-nação à era das TIC. D.E.L.T.A., São Paulo, v. 25, n. 1, p. 1-38, 2009.

BUZATO, M. E. K. O letramento eletrônico e o uso do computador no ensino de lingua estrangeira: contribuições para a formação de professores. $2001.189 \mathrm{f}$. Dissertação (Mestrado) - Instituto de Estudos da Linguagem, Universidade Estadual de Campinas, Campinas, SP. Disponível em: <http://libdigi.unicamp.br/ document/?down=vtls000219553>. Acesso em: 5 jan. 2010.

CAMPION, M. G. Technophilia and technophobia. Australian Journal of Educational Technology, v. 5, n. 1, p. 23-36, 1989. Disponível em: <http:// www.ascilite.org.au/ajet/ajet5/campion.html>. Acesso em: 20 mar. 2011.

CASTELLS, M. A Sociedade em Rede. 6. ed. A era da informação: economia, sociedade e cultura, v. 1. São Paulo: Paz e Terra, 1999.

CHARTIER, R. A aventura do livro: do leitor ao navegador. Tradução de Reginaldo de Moraes. São Paulo: Editora UNESP, 1999.

COMMITTEE ON INFORMATION TECHNOLOGY LITERACY. Being Fluent with Information Technology. Washington, DC: National Academy Press, 1999. Disponível em: <http://www.nap.edu/catalog/6482.html>. Acesso em: 30 dez. 2010. 
COSCARELLI, C. V. Alfabetização e Letramento digital. In: COSCARELLI, C. V.; RIBEIRO, A. E. (Orgs.). Letramento digital: aspectos sociais e possibilidades pedagógicas. 2. ed. Belo Horizonte: Ceale; Autêntica, 2007. p. 25-40.

DAVIES, B.; HARRÉ, R. Positioning: the discursive production of selves. Journal for the Theory of Social Behavior, v. 20 (1), p. 43-63, 1990.

FRADE, I. C. A. S. Alfabetização digital: problematização do conceito e possíveis relações com a pedagogia e com a aprendizagem inicial do sistema de escrita. In: COSCARELLI, C. V.; RIBEIRO, A. E. (Orgs.). Letramento digital: aspectos sociais e possibilidades pedagógicas. 2. ed. Belo Horizonte: Ceale; Autêntica, 2007. p. 29-83. HARRÉ, R.; VAN LANGENHOVE, L. (eds). Positioning Theory: moral contexts of intentional action. Oxford and Massachussets: Blackwell Publishers, p. 1-13, 1999. KATO, M. A. No mundo da escrita: uma perspectiva psicolingüistica. São Paulo: Ática, 1986.

KLEIMAN, A. B. Modelos de letramento e as práticas de alfabetização na escola. In: KLEIMAN, A. B. (Org.). Os significados do letramento: uma nova perspectiva sobre a prática social da escrita. Campinas, SP: Mercado de Letras, 1995. p. 15-61. LEMKE, J. L. Travels in Hypermodality. Visual Communication, London, v. 1(3), p. 299-325, 2002.

LEVY, P. Cibercultura. São Paulo: Editora 34, 1999.

PRENSKY, M. Digital Natives, Digital Immigrants. On the Horizon, v. 9, n. 5, p. 1-6, October 2001. Disponível em: <http://www.marcprensky.com/writing/ prensky\%20-\%20digital\%20 natives, \%20digital\%20immigrants\%20$\% 20$ part1.pdf $>$. Acesso em: 20 fev. 2011.

SACKS, H.; SCHEGLOFF, E. A.; JEFFERSON, G. A simplest systematic for the organization of turn-taking for conversation. Language, v. 50, p. 696-735, 1974. SACKS, H.; SCHEGLOFF, E. A.; JEFFERSON, G. Sistemática elementar para a organização da tomada de turnos para a conversa. Veredas, Juiz de Fora, v. 7, n. 1/2, p. 9-73, 2005.

SAITO, F. S. (Multi)Letramento(s) Digital(is) na escola pública: reflexōes sobre as práticas discursivas de professoras que se relacionaram com as Tecnologias da Informação e Comunicação no ensino. 2011. 143 f. Dissertação (Mestrado) Programa de Pós-Graduação em Linguística, Universidade Federal de Juiz de Fora, Juiz de Fora, MG.

SAITO, F. S.; SOUZA, P. N. (Multi)letramento(s) digital(is): por uma revisão de literatura crítica. Linguagens e diálogos, v. 2, n. 2, p. 109-143, 2011. Disponível em: <http://linguagensedialogos.com.br/2011.1/textos/19-artfabiano-patricia.pdf $>$. Acesso em: 15 dez. 2011. 
SELBER, S. A. Multiliteracies for a Digital Age. Carbondale: Southern Illinois University Press, 2004.

SNYDER, I. (Ed.). Page to Screen: Taking Literacy Into the Electronic Era. London, New York: Routledge, 1996.

SOARES, M. Letramento e alfabetização: as muitas facetas. Revista Brasileira de Educação, n. 25, p. 5-17, Abril 2004. Disponível em: <http://www.scielo.br/ pdf/rbedu/n25/n25a01.pdf>. Acesso em: 18 jun. 2010.

SOARES, M. Novas práticas de leitura e escrita: letramento na cibercultura. Educação e Sociedade, Campinas, v. 23, n. 81, p. 143-160, 2002. Disponível em: $<$ http://www.cedes.unicamp.br>. Acesso em: 20 jan. 2009.

STREET, B. V. Literacy in Theory and Practice. Cambridge; New York and Melbourne: Cambridge University Press, 1984.

TAKAHASHI, T. (Org.). Sociedade da informação no Brasil: livro verde. Brasília: Ministério da Ciência e Tecnologia, 2000.

TERUYA, K. T. Trabalho e educação na era midiática. Maringá: Editora da UEM, 2006.

TFOUNI, L. V. Adultos não alfabetizados: o avesso do avesso. Campinas: Pontes, 1988.

TFOUNI, L. V. Letramento e alfabetização. São Paulo: Cortez, 1995.

ERRATA: a nota "a segunda autora, Profa. Dra. Patrícia Nora de Souza Ribeiro, atuou como orientadora do trabalho" foi inserida no artigo em fevereiro/2013. 